EPiC Series in Language and Linguistics
Volume 2, 2017, Pages 52-59
Professional and Academic Discourse:
an Interdisciplinary Perspective

\title{
The Influence of the Mother Tongue on the Use of Metaphor in English as a Second Language in Higher Education Students
}

\author{
Oleksandra Iaroslavtseva and Hanna Skorczynska \\ Universitat Poltècnica de Valencia, Valencia, Spain \\ olia@posgrado.upv.es, hskorczy@idm.upv.es
}

\begin{abstract}
Metaphor has been widely recognized as a central tool of our cognitive apparatus, motivating the widespread use of metaphorical words and expressions in language and discourse. Therefore, it is important for language learners to use metaphors in the target language appropriately. The influence of the mother tongue on the use of metaphors in essays written by Spanish learners of English was analysed. Three corpora were used for this study: the experimental corpus contained 100 essays of Spanish-speaking learners of English, 50 with B2 level and 50 with C1 level (CEFR). The other two corpora were used as reference corpora: the British National Corpus (BNC) and the Corpus de Referencia del Español Actual (CREA). MIPVU method (Steen et al., 2010) was used to identify metaphors in the experimental corpus. The quantitative analysis showed that the influence of Spanish on errors in metaphors is higher at B2 level than at C1 level. The results of the analysis are especially helpful for learners and teachers of English as a Foreign Language as well as for testing researchers.
\end{abstract}

\section{Introduction}

Language system provides its users with a broad range of resources to convey factual information, but also to transmit feelings. The choice of specific words depends on the communicative intention of a language user: making an intended impression, causing a specific reaction or expressing the depth of feelings. One of the means to reach such communicative goals is metaphor.

The study of metaphor traces back to the ancient times of Aristotle. At that time, he regarded metaphor from the perspective of rhetoric and stated that "Metaphor consists in giving the thing a name that belongs to something else; the transference being either from genus to species, or from species to genus, or from species to species, or on grounds of analogy” (Barnes, 2014: 2332).

However, nowadays, we are interested in metaphor from the perspective of cognitive linguistics. According to Lakoff and Johnson (1980), metaphor serves as a basic mental operation, as a way of 
perceiving, structuring, and explaining the world. These two linguists largely influenced the development of cognitive metaphor theory. They stated that our speech is metaphorically constructed and that metaphor itself is not a deviation from the norm and is used not only in poetry, but it is rather a phenomenon of everyday language.

With the development of cognitivism other points of view, regarding metaphor as a cognitive element of speech, emerged. Thus, metaphor was proposed to be considered not only as a stylistic device, but also as a language unit, that facilitates short and colourful description of phenomena of our perceptual world that are difficult to transmit (Weber, 1995).

Nowadays with the application of metaphor to second language teaching and learning, more and more language researchers are becoming interested in the value of metaphor in pedagogical context (Kövecses, 2001; Dirven, 2001; Piquer Píritz, 2008; Tyler, 2008; MacArthur, 2010), given that metaphor is ubiquitous both in thought and language (Deignan, 2005; MacArthur, 2010; Littlemore et al., 2013). A number of studies showed the benefits of the use of metaphor in language learning, for instance, metaphor helps to develop reading skills (Boers, 2000; Holme, 2004; Carter \& MacCarthy, 2014), and also facilitates vocabulary learning (MacLennan, 1994; Taylor, 2003). However, much of this research has been concerned with how to help learners to understand metaphors in the target language, rather than how to produce metaphors. Some scholars have emphasized the importance of improving the metaphoric competence of students of English as a foreign language (Low, 1988; Ponterotto, 1994; Littlemore \& Low, 2006; MacArthur, 2010; Littlemore et al., 2013).

A lot of research has been done to analyse L1 influence in the process of second language acquisition, however too little attention has been paid to L1 influence on the use of figurative language. The results of studies in the field of idioms showed that L1 knowledge helps to understand identical and similar idioms, however it interferes in comprehension of completely different idioms and in the production of idioms in tests (Irujo, 1986; Charteris-Black, 2002; Chen \& Lai, 2013). In addition, L1 influence on the use of idioms is higher at the beginning and at advanced stages of L2 learning (Kellerman, 1987). As to the studies that focus on metaphor in particular, their results showed that L1 influence is evident in the use of metaphors in written production, as L1 metaphors are calqued in the L2 (MacArthur, 2010; Erel et al., 2015). With regard to the studies of L1 influence on metaphors at different CEFR levels, Littlemore and colleagues (2013) looked into the use of metaphors by Germanspeaking learners of English. They examined 25 essays (five at each level A2, B1, B2, C1, C2) for the use of metaphor and observed that there is more evidence of the influence of German at B2 level than at other levels.

Given the findings of the previous studies, efforts in the analysis of the L1 influence on the use of metaphors seem relative lacking. This study aims to fill the gap and contribute to a better understanding of the metaphoric use. The main aim of this study is to analyse the influence of Spanish on the use of metaphors in essays written by learners of English. The study has four objectives:

1. to measure the frequency of linguistic metaphors produced by Spanish learners of English at levels B2-C1 in written texts.

2. to identify the frequency of use of open- and closed-class metaphorical items.

3. to identify metaphors involving some kind of error.

4. to identify and classify metaphors involving some kind of error produced by the influence of L1.

Therefore, this study seeks to answer the following research questions:

1. In what ways does the frequency of linguistic metaphors produced vary across CEFR levels B2-C1 for Spanish-speaking learners of English? 
2. Which metaphorical items, open- or closed-class items, are used by Spanish learners more frequently at each of the levels analysed?

3. To what extent do learners make errors in the use of metaphors?

4. Is there any influence of the native language on such errors?

\section{Corpora and Procedure}

To address the above research questions three corpora were used: an experimental corpus and two reference corpora. The experimental corpus was compiled and contained 100 essays of Spanishspeaking learners of English, 50 with B2 level and 50 with C1 level, following the description of the Common European Framework of Reference for Languages of the European Council (2001). The other two corpora were used as reference corpora: the British National Corpus (BNC) for the English language and the Corpus de Referencia del Español Actual (CREA) for the Spanish language.

The essays were written by 100 Spanish-speaking students who studied a bachelor degree at the Universitat Poltècnica de Valencia, Spain. Both masculine and feminine participants were included in the study, aged between 18 and 25. However, gender was not considered in our study, so the data were not included in the analysis.

For our study, we used 50 essays with B2 level that had an average length of 120-170 words, and 50 with C1 level that had an average length of 200-250 words. The total number of words in the experimental corpus amounts to 19,508. The essays covered different topics, some of them were for example 'college', 'parents' role', 'cooking', 'holidays' and 'public transport'.

The study was based on a mixed research method: qualitative and quantitative. The Metaphor Identification Procedure Vrije Universiteit (MIPVU) (Steen et al., 2010) was used to identify all of the metaphorically used words and expressions in the corpus. Following this procedure, we examined each text on a word-by-word basis in order to find metaphor-related words. Then we compared the basic and the contextual meaning of such words, when the contextual meaning contrasts with the basic meaning we marked the word as metaphorically used.

According to Krennmayr (2008: 113) dictionaries should be used “...as a tool to support the intuitions of the analyst". Therefore, the main tool that was used to make a decision whether a lexical unit could be annotated as a metaphor, was the Macmillan English Dictionary for Advanced Learners (Rundell, 2002), following Steen and colleagues (2010). In cases of doubt, we also used the Longman Dictionary of Contemporary English (2015), as suggested in MIPVU procedure (Steen et al., 2010), however we used a newer and revised version of this dictionary. In addition, we used the Collins Spanish Dictionary (English-Spanish, Spanish-English) (2005) to get all possible translations of non-native like lexical units that were used metaphorically by Spanish learners of English.

Once the metaphors had been identified following this procedure, the metaphor frequency of texts was calculated by finding the percentage of metaphorically used lexical units in relation to the total number of lexical units in each text. Then we categorized metaphors into open- and closed-class items in order to find out if there was any difference in the use of metaphors at each of the levels analysed. The next step consisted in calculating to which extent the learners used these items.

After that, each metaphorically used lexical unit was queried in the BNC corpus. When the search gave us no concordances, we were able to annotate this metaphor as a non-native like phraseology, and therefore deduce that it was an error made by Spanish learners. Once all the metaphors had been checked in this way, we calculated the total number of erroneous metaphors. Error scoring was calculated using the same formula as earlier. 
Once the erroneous metaphors had been identified, they were translated into Spanish and compared with the Spanish Corpus CREA in order to see if there was any L1 influence on the use of each of these metaphors.

When we identified all L1-influenced metaphors we classified them according to the type of error.

\section{Results and Discussion}

The results of the quantitative analysis are shown in Table 1 . The figures represent the total number of occurrences of metaphors at B2 and C1 levels in the experimental corpus.

\begin{tabular}{cccc}
\hline Level & Number of lexical units & Number of metaphors & Metaphor Frequency \\
\hline B2 & 7,078 & 270 & $3.8 \%$ \\
\hline C1 & 12,235 & 664 & $5.4 \%$ \\
\hline
\end{tabular}

Table 1: Frequency of the use of metaphors at B2 and C1 levels

Taking into account these data, we can argue that the proportion of metaphors used by language learners increases across the levels B2 and C1. It is important to note that not only the language knowledge of learners increases across these levels, as expected, but the metaphorical competence as well. Then, as we were also interested in the use of metaphors containing prepositions, we decided to categorise the metaphors identified as open-class and closed-class metaphorical items (See Table 2). Open-class metaphorical items include nouns, verbs, adjectives and adverbs, and can express any conceptual metaphor, whereas closed-class metaphorical items include prepositions, conjunctions and determiners, and can express only a finite set of meanings (Sullivan, 2013: 125).

\begin{tabular}{cccc}
\hline Level & Total metaphors & Open-class metaphors & Closed-class metaphors \\
\hline B2 & 270 & $145(54 \%)$ & $125(46 \%)$ \\
\hline C1 & 664 & $449(68 \%)$ & $215(32 \%)$ \\
\hline
\end{tabular}

Table 2: Open- and closed-class metaphors at B2 and C1 levels

Looking at these results, we can note that more open-class metaphors than closed-class metaphors are used at both levels analysed. We can also see that the proportion of open-class metaphors increased from B2 level to C1 level. Such increase was also observed in the research of Littlemore and colleagues (2013), where in both groups analysed (German- and Greek-speaking learners of English) the proportion of open-class metaphors overtook the proportion of closed-class metaphors at B2 level and continued to increase across higher levels (C1 and C2).

As the main aim of this study was to analyse the influence of Spanish on the use of metaphors in essays written by learners of English, the next step was to identify erroneous metaphors, and analyse them to find out if there was any L1 influence on the use of such metaphors. As a result of this analysis it is possible to state that at both levels analysed, the influence of the native language, in our case Spanish, on the use of metaphors is notable. In example (1), a learner with B2 level wrote:

(1) My grandmother believes that cooking with love for your family can open your soul. 
In this sentence, we can see a calque of the conventional Spanish metaphor 'abrir el alma', and in the BNC corpus, used as a reference corpus, no occurrences of 'open your soul' were found.

In example (2), a learner with C1 level wrote:

(2) If metros and buses circulate more often, more people would use them.

In this case, we can note that the direct translation from Spanish 'los autobuses circulan'. In English the verb 'circulate' is inappropriate, and in this sentence, the verb 'run' would have been a better choice.

Table 3 includes the percentages of the erroneous metaphors with a clear influence of Spanish.

\begin{tabular}{cccc}
\hline Level & Number of metaphors & Erroneous metaphors & $\begin{array}{c}\text { L1 influence on erroneous } \\
\text { metaphors }\end{array}$ \\
\hline B2 & 270 & $57(21 \%)$ & $30(53 \%)$ \\
\hline C1 & 664 & $125(19 \%)$ & $53(42 \%)$
\end{tabular}

Table 3: L1 influence on errors containing metaphor at B2 and C1 levels

We can observe that the overall number of metaphors containing errors is higher at B2 level. The rates of L1 influence on such metaphors are also much higher at B2 level. Therefore, we may conclude that B2 learners rely heavily on their mother tongue.

In our experimental corpus we were able to identify the following types of errors in metaphorically used words, which were influenced by Spanish:

1. Wrong word choice:

I have an English exam in this date.

In this case, the learner has chosen the wrong preposition, and this choice might be due to the influence of his/her mother tongue, as in Spanish a preposition 'en' is used in the phrase 'en esta fecha'. The appropriate English preposition in this context is 'on'.

2. Words that exist in Spanish and are similar to some words in English, but have different meanings, i.e. false friends.

A touristic destiny due to its beaches and gastronomy.

In this sentence, the learner uses the word 'destiny' as it is similar to the Spanish noun 'destino'. However, in English 'destiny' has a different meaning. According to the Macmillan English Dictionary for Advanced Learners (Rundell, 2002), the basic meaning of the word 'destiny' is 'the things that you will do, or the type of person that you will become, in the future', whereas according to the Collins Spanish Dictionary (2005) the word 'destino' could be translated in English in different ways:

a) destiny, fate

b) destination

c) job, post, placement

Therefore, in this example, we can see that the learner has failed to choose the appropriate translation of the word 'destino' in the given context, relying on the mother tongue. In this case, the correct choice in English would have been the noun 'destination'.

3. Direct translation of the metaphoric phrase from Spanish to English, which makes no sense in English. 
There is no colour for me, I prefer it in the outside.

Native speakers of Spanish would understand this expression without any problems, as it was calqued from the Spanish idiomatic expression 'no hay color', which means in English 'there is no comparison'. However, for native speakers of English this expression might cause comprehension problems.

4. Non-native like metaphors used quite creatively by Spanish-speaking learners (not found in the BNC, but found in the CREA)

The speed of our lives is sometimes like a Formula 1 drifting in Monaco race: lots of "I must do", "I’m late for”, “Oh! I can’t stand because...” leads our journeys.

This example illustrates how creatively a Spanish-speaking learner with C1 level uses metaphors. In this sentence we underlined only the metaphorically used word that is non-native like. It would have been more appropriate to use the word 'tempo' in English, however the learner uses the metaphor 'speed' that is a direct translation from the Spanish noun 'velocidad'.

\section{Conclusions}

This study provides preliminary insights into the use of metaphors in essays written by Spanishlanguage speakers at B2 and C1 English levels. Significant differences in the use of metaphors at these levels have been shown. The major findings of our study are that the proportion of metaphors used by Spanish-speaking learners of English increases across the levels B2 and C1. In addition, more openclass metaphors than closed-class metaphors are used at both levels analysed, and the proportion of open-class metaphors increased from B2 level to C1 level. We also found that the overall number of erroneous metaphors is higher at B2 level, as well as the rates of L1 influence on such metaphors. Therefore, we were able to conclude that B2 learners rely heavily on their mother tongue. Also, based on the data from our experimental corpus we made a classification of L1-influenced errors, which includes four different types of such errors.

The findings of this investigation confirm and complement those of earlier studies (Littlemore et al., 2013; MacArthur, 2010) and contribute additional evidence suggesting that special attention needs to be paid to both metaphor comprehension and metaphor use in L2, especially at the levels studied. However, some limitations have to be pointed out. This study has focused only on two levels, B2 and C1, and further investigation will need to include other levels of the CEFR (2001), in order to find out how L1 influence on the use of metaphors varies across all these levels. Future work will also include a more detailed classification of different types of L1-influenced errors.

The results of the analysis are especially helpful for learners and teachers of English as a Foreign Language as well as for testing researchers. 


\section{References}

Barnes, J. (Ed.). (2014). Complete Works of Aristotle, Volume 1: The Revised Oxford Translation (Vol. 1). Princeton: Princeton University Press.

Boers, F. (2000). Enhancing metaphoric awareness in specialised reading. English for specific purposes, 19(2), 137-147.

Carter, R., \& McCarthy, M. (2014). Vocabulary and language teaching. London: Routledge.

Charteris-Black, J. (2002). Second language figurative proficiency: A comparative study of Malay and English. Applied Linguistics, 23(1), 104-133.

Chen, Y., \& Lai, H. (2013). The influence of cultural universality and specificity on EFL learners' comprehension of metaphor and metonymy. International Journal of Applied Linguistics, 24(3), 312336.

Collins Spanish Dictionary. (2005). Collins. $8^{\text {th }}$ Edition.

Council of Europe. (2001). Common European Framework of Reference for Languages: Learning, Teaching, Assessment. Cambridge: Cambridge University Press.

Deignan, A. (2005). Metaphor and corpus linguistics (Vol. 6). Amsterdam/Philadelphia: John Benjamins Publishing.

Dirven, R. (2001). English phrasal verbs: Theory and didactic application. Applied cognitive linguistics, 2, 3-28.

Erel, S., Bulut, D., \& Mannasoglu, H. (2015). A corpus-based study of Turkish EFL students' metaphorical language use in writing. Third International Learner Corpus Research Conference, 6062.

Holme, R. (2004). Mind, metaphor and language teaching. New York: Palgrave Macmillan.

Irujo, S. (1986). Don't put your leg in your mouth: Transfer in the acquisition of idioms in a second language. Tesol Quarterly, 20(2), 287-304.

Kellerman, E. (1987). Aspects of transferability in second language acquisition. Unpublished Ph.D. Dissertation, University of Nijmegen.

Kövecses, Z. (2001). A cognitive linguistic view of learning idioms in an FLT context. Applied cognitive linguistics II: Language pedagogy, 87-115.

Krennmayr, T. (2008) Using dictionaries in linguistic metaphor identification. In N.L. Johannesson \& D.C. Minugh (Eds.), Selected Papers from the 2006 and 2007 Stockholm Metaphor Festivals (pp. 97-115). Stockholm: Department of English, Stockholm University.

Lakoff, G. \& Johnson, M. (1980). Metaphors We Live By. Chicago IL: University of Chicago Press.

Littlemore, J., \& Low, G. (2006). Metaphoric competence, second language learning, and communicative language ability. Applied Linguistics, 27(2), 268-294.

Littlemore, J., Krennmayr, T., Turner, J., \& Turner, S. (2013). An investigation into metaphor use at different levels of second language writing. Applied linguistics, 35(2), 117-144.

Longman Dictionary of Contemporary English. (2015) Pearson Education ESL. $6^{\text {th }}$ Edition.

Low, G. (1988). On teaching metaphor. Applied Linguistics, 9(2), 125-147.

MacArthur, F. (2010). Metaphorical competence in EFL: Where are we and where should we be going? A view from the language classroom. AILA Review, 23(1), 155-173.

MacLennan, C. H. (1994). Metaphors and prototypes in the learning teaching of grammar and vocabulary. IRAL-International Review of Applied Linguistics in Language Teaching, 32(2), 97-110.

Piquer-Piriz, A. M. (2008). Young learners' understanding of figurative language. In M. Zanotto, L. Cameron \& M. Cavalcanti (Eds.), Confronting Metaphor in Use: An Applied Linguistic Approach (pp. 183-198). Amsterdam/Philadelphia: John Benjamins.

Ponterotto, D. (1994). Metaphors we can learn by. English Teaching Forum, 32(3), 2-7.

Pragglejaz Group. (2007). MIP: A method for identifying metaphorically used words in discourse. Metaphor and Symbol, 22(1), 1-39. 
Rundell, M. (Ed.). (2002). Macmillan English dictionary for advanced learners. Oxford: Macmillan Publishers.

Steen, G. J., Dorst, A. G., Herrmann, J. B., Kaal, A. A., \& Krennmayr, T. (2010). A method for linguistic metaphor identification: From MIP to MIPVU. Amsterdam/Philadelphia: John Benjamins.

Sullivan, K. (2013). Frames and constructions in metaphoric language (Vol. 14). Amsterdam/Philadelphia: John Benjamins Publishing.

Taylor, J. R. (2003). Polysemy's paradoxes. Language sciences, 25(6), 637-655.

Tyler, A. (2008). Cognitive linguistics and second language instruction. Handbook of cognitive linguistics and second language acquisition, 456-488.

Weber, F. (1995). Denken in Metaphern. Kognitive Semantik und französische Gefühlsmetaphorik. Frankfurt am M.: Lang. 